\title{
Developing a deeper understanding of mathematics teaching expertise: an examination of three Chinese mathematics teachers' resource systems as windows into their work and expertise
}

\author{
Birgit Pepin ${ }^{1} \cdot$ Binyan $\mathrm{Xu}^{2} \cdot$ Luc Trouche ${ }^{3}$. \\ Chongyang Wang ${ }^{2,3}$
}

Published online: 17 September 2016

(C) The Author(s) 2016. This article is published with open access at Springerlink.com

\begin{abstract}
In order to develop a deeper understanding of mathematics teaching expertise, in this study we use the Documentational Approach to Didactics to explore the resource systems of three Chinese mathematics "expert" teachers. Exploiting the Western and Eastern literature we examine the notion of "mathematics teaching expertise", as it is perceived in the East and the West. The data consist of two rounds of in-depth interviews, observations and teachers' representations of their resource systems, where teachers describe their resources connected to their practice, their perceptions of mathematics teaching expertise, and how to develop it. Subsequently, the data are analyzed with respect to the different facets of the notion of teaching expertise and related to the teachers' views and practices, in order to deepen our understandings of what proficiency in mathematics teaching might mean and how to develop it, seen through the lens of 'resources'. The significance of the study relates to the enhancement of mathematics teachers' expertise and capacity building when working in collectives (e.g., in teacher professional development), in order to develop a strong workforce for supporting and helping to improve pupil learning.
\end{abstract}

Keywords Mathematics teachers $\cdot$ Mathematics teaching expertise $\cdot$ Resource/s · Documentational approach of didactics · China

Birgit Pepin

b.e.u.pepin@tue.nl

1 Eindhoven School of Education, Technische Universiteit Eindhoven, Eindhoven, The Netherlands

2 Institute of Curriculum and Instruction, East China Normal University, Shanghai, China

3 Institut Français de l'Education, Ecole Normale Supérieure de Lyon, Lyon, France 


\section{Introduction}

Regarding the notion of mathematics teaching expertise, there have been several studies investigating "expert" teachers' characteristics as compared to those of "novice" teachers in Western countries (e.g., Berliner, 1987). More recently, possibly triggered by the success of Chinese Shanghai students in studies such as PISA and TIMSS (OECD, 2010), much attention has been given to studying mathematics teachers in mainland China and Shanghai (e.g., Li \& Huang, 2008), and one of the particular areas of interest is the nature of their expertise in mathematics teaching (e.g., Ma, 1999). However, at a more general level there is insufficient knowledge of the nature of teacher expertise in mathematics education (e.g., Li \& Kaiser, 2011), and hardly any relating such expertise to teachers' resources and how they work with these resources in their daily practice. We define teachers' resources as the curriculum/text, material and personal resources that teachers use and develop in their daily practice, in and for their teaching.

As it is generally acknowledged that mathematics teaching is a cultural activity (e.g., Stigler \& Hiebert, 1999), we assume that this is also likely to be the case with mathematics teaching expertise. At the same time research (e.g., Blömeke \& Kaiser, 2012) suggests that teaching quality may be one of the most important factors in student learning, and Shanghai students have been recognized to perform outstandingly as compared to their Western counterparts. Hence, in order to develop deeper insights into the notion of mathematics teaching expertise, we have investigated three Chinese "expert teachers" through the lens of their resource systems aligned to their practice, and from different cultural and theoretical perspectives (Eastern and Western).

The research questions are:

(1) How do three Chinese "expert" mathematics teachers describe their resource systems; which kinds of resources do they use in/for their daily practice?

(2) How do the three case teachers perceive expertise in teaching mathematics, and how to develop such expertise?

(3) What are the characteristics of the three teachers' resource systems, and in which ways do they characterize mathematics teaching expertise?

After this general introduction, we propose, in the second section, a literature review focusing on the notion of mathematics teaching expertise. In the third section we detail the crucial notion of a resource system, drawing on the documentational approach of didactics (Gueudet \& Trouche, 2009). The methodological considerations concerning the research design, the data collection strategies and analyses are presented in the fourth section. In the fifth section, we present our findings, and in the final section we conclude by developing deeper understandings of mathematics teaching expertise through the lens of resources, and by indicating the significance of this work for teacher professional development.

\section{Background literature: mathematics teaching expertise}

In the educational research literature 'good' or 'effective' teaching are contested notions (Fenstermacher \& Richardson, 2005). According to Morris and Hiebert (2011), good teaching can be defined in relation to specific goals, and "if learning goals are valued and students are achieving them more effectively, then teaching is improving” (p. 10). In Cai and Wang's (2010) study comparing Chinese and US teachers' beliefs concerning 'effective mathematics teaching', 
they found that the two groups of teachers perceived 'effectiveness' very differently, and the team interpreted these differences as reflections of "distinctive underlying cultural beliefs and values". Hence, we consider that the notion of mathematics teaching expertise might be differently construed in the Western/Anglo-American and the Eastern/Chinese literature. ${ }^{1}$

As part of the Anglo/American research sphere, one of the forerunners of research into 'expert teachers' and their characteristics has been Berliner $(1987,2004)$. He established that "expertise is specific to a domain, and to particular contexts in domains" (p. 13). Furthermore, he developed a heuristic, five-stage model of teacher development: Novice; Advanced beginner; Competent; Proficient; and Expert. Berliner (2004) describes characteristics that are said to relate to expert teachers, amongst them 'extensive pedagogical content knowledge, including deep representations of subject matter knowledge'; and 'better monitoring of learning and providing feedback to students'. Berliner claims that in his research he found evidence that those identified as experts were able to enhance students' learning skills and test scores (beyond that of non-experts). At the same time there have been many studies, which contest the notion of 'expert teacher' (e.g., Olson, 1992).

The concept of 'pedagogical content knowledge', first articulated by Shulman (1986), has since been prominent, and developed in mathematics education, in research on experienced versus student teachers. Moreover, the notion of "Mathematical Knowledge in/for Teaching" (e.g., Ball, Thames, \& Phelps, 2008; Rowland \& Ruthven, 2011) has been central in discussions on developing the notion of quality of instruction (Hill et al., 2008), and to emphasize the features of the concept of expertise.

Anchored in previous research, Schoenfeld and Kilpatrick (2008) developed a framework for 'proficiency in teaching mathematics' (p. 321), with the following seven strands: knowing school mathematics in depth; knowing students as thinkers; knowing students as learners; crafting and managing learning environments; developing classroom norms and supporting classroom discourse as part of "teaching for understanding"; building relationships that support learning; and reflecting on one's practice. Each of the seven strands contains a considerable body of literature reporting on research in the field and outlining particular dimensions of each strand.

Interestingly, most Chinese studies in the field agree that (1) there are expert mathematics teachers, and they are characterized in only slightly different ways; and that (2) there are at least three dimensions of expert teachers' characteristics (with varying nuances): knowledge; skills/abilities; and personal attributes (Yang, 2010, pp. 30-31). Li, Huang, and Yang (2011) also report on the pedagogical content knowledge (PCK) of expert teachers in mainland China, which appeared to be highly developed and nuanced. Ma (1999) talks about "knowledge packages" which are said to be necessary for mathematics teachers to teach proficiently; and "knowledge packages" are characterized by a Profound Understanding of Fundamental Mathematics (PUFM).

One of the most known studies on expert teachers was conducted by Yang (2010): he explored how mathematics educators in mainland China conceptualized expert teachers. The study not only provides characteristics of expert mathematics teachers, but also how the Chinese social and cultural-educational traditions (and the context) influenced those perceptions. Yang (2010) proposed the following roles an expert mathematics teacher should/is perceived to play: that of (1) a researcher (e.g., to conduct research and publish articles); (2) a teacher educator (e.g., to mentor non-expert teachers and help them to

\footnotetext{
${ }^{1}$ We use related notions (e.g., 'proficiency in teaching mathematics'; 'expert teacher/ teaching') for our purpose.
} 
develop professionally); (3) a scholar (e.g., regarding PCK, curriculum theory and examinations); and (4) an exemplary model for students and colleagues.

In China (and East Asia in general) there is also an extensive amount of literature on how to develop expertise in teaching mathematics. This development is said to be supported by different efforts, for example: establishment of master work stations (e.g., Li, Tang, \& Gong, 2011); Chinese lesson study development (e.g., Huang, Su, \& Xu, 2014).

In summary, it appears that the American/Anglo-Saxon literature theorizes more extensively about connotations and characteristics of what mathematics teaching expertise might entail, whereas the Chinese (English written) literature reflects the various practicalities of developing such expertise. Interestingly, the Chinese view of an expert teacher includes personal traits: to have a 'noble personality' (Yang, 2010), and to serve as an example to students and colleagues. Clearly, the Western/American and the Chinese notions of mathematics teaching expertise are likely to be underpinned by cultural values and different perceptions of the influences of teaching. Whilst one outlines the rational factors of proficiency; the other relates to a more 'wholesome', humanly all-encompassing view of the expert teacher.

In the present study we look through the 'lens of resources' (see below) to develop deeper understandings of mathematics teaching expertise, or proficiency in teaching mathematics; and the processes/stages of developing that expertise.

\section{Theoretical framework}

We draw in this paper on the documentational approach to didactics (Gueudet, Pepin, \& Trouche, 2012; Gueudet \& Trouche, 2009), which acknowledges the central role of resources for teachers' work. In particular, this approach emphasizes the dialectic nature of the relationships between teachers and resources; and the core concept of a teacher's resource system.

As noted earlier, we define teachers' resources as the curriculum/text, material and personal resources that teachers use in their daily practice, in and for their teaching. A teacher is permanently exposed to a large variety of resources and s/he interacts with these resources to prepare and conceive his/her instruction. The Internet has dramatically increased the amount of available resources, opening new opportunities (e.g., using dynamic geometry software), and for conceiving and sharing resources at a large scale.

The documentational approach maintains three main concepts introduced by Rabardel (1995): instrumentation; instrumentalisation; and genesis (Fig. 1). For performing a teaching task, a teacher interacts with a set of resources. This interaction combines two interrelated processes: the process of instrumentation, where the selected resources support and influence the teacher's activity; and the process of instrumentalisation, where the teacher adapts the resources for his/her needs.

This productive interaction between a teacher and a set of resources, guided by a teaching goal, through successive stages of (re-)design and implementation in class, gives birth to a hybrid entity, a document: this consists of the resources adapted and re-combined/designed; the implicit and intended usages of these resources; and the mathematical knowledge guiding these usages (content knowledge; PCK; knowledge about these resources). We name this hybrid entity a document, as something 


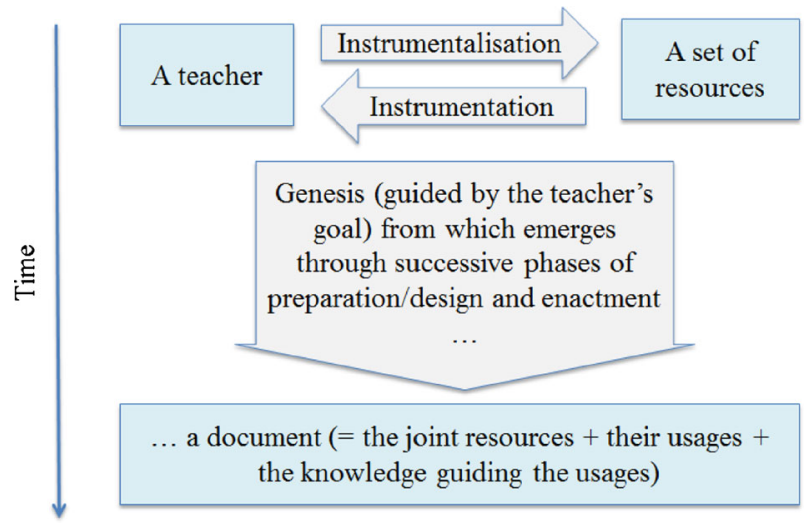

Fig. 1 A schema of a documentational genesis

documenting a teacher's activity, and we name the process, leading from a set of resources to a document, documentational genesis.

In order to understand the relationships between teachers and resources, we need to consider the whole set of resources with which a teacher works. We name this set the teacher resource system, meaning that this set is a structured entity, aligned with mathematics teachers' practices. What we have learnt from the analysis of teachers' resource systems (e.g., Gueudet, Pepin, \& Trouche, 2013) is that such systems can be structured according to different dimensions: schooling level/grades; mathematical topic areas (e.g., resources for teaching fractions); kinds of mathematical activity (e.g., resources for working with students); the level of documentational genesis regarding their design (e.g., a resource downloaded from the Internet; adapted or designed by the teacher him/herself); and/or potential sharing with colleagues (e.g., resources not shared; or with particular colleagues).

The documentational approach also calls for special methodological tools, exploiting teachers' views on the use of their resources. Among those, the SRRS (Schematic Representation of a teacher's Resource System) is based on the drawing/ representation (by the teacher him/herself) of his/her resources with respect to the different activities associated with those resources.

\section{Context and methods}

In this section we describe teachers' working conditions in China; the school context; and the methodological approach including the data collection strategies and data analysis.

\subsection{Chinese mathematics teachers' working conditions}

Conducted in 29 provinces in China, Ding's (2010) study showed that primary and secondary school teachers have to teach 12 lessons per week; high school teachers 13 lessons. In middle schools most teachers teach only one discipline, and they typically have two classes. In Ding's study (p. 146) $87.6 \%$ of Chinese teachers participated in teaching research activities in the frame of a Teaching Research Group (TRG) at least once per month; and $54.4 \%$ of 
teachers participated at least once per week. In recent years nearly every school has developed (subject-specific) TRGs, so that teachers can develop and improve their instruction in discussion with colleagues and experts: TRGs are professional learning communities at school level, for collective lesson preparation and classroom teaching evaluation. The improvement of Internet communication also led to the development of online discussion groups on the national QQ platform. ${ }^{2}$

\subsection{Context of the school}

Built in 2004, high school X is located in Suzhou (Jiangsu Province), and it has a school population of 1182 students (in 34 classes) and 136 teachers. In the year we conducted the study, the average age of teachers was 38 years, with an average of 15 years teaching experience. The school had an excellent reputation: in recent years the whole team of teachers had been awarded the title of "excellent teacher community in Suzhou". More particularly, the mathematics TRG (which included all mathematics teachers of this school) had been given the title "model of teaching experimental reform in Jiangsu province": it had developed a schoolbased curriculum, which was the result of a school-based research project.

In this school teachers of the same discipline shared a large office, providing opportunities for exchange of ideas and for discussing problems face-to-face. Each teacher was equipped with a computer (by the school). At least three official mathematics QQ groups were available for each teacher (at school, district, and city level). Beside the QQ groups, the school had its own platform, allowing teachers to submit and download documents, such as lesson plans and courseware shared by others, teaching resources purchased by the school, and the official government documents.

In terms of resources, teachers have many resources to choose from, albeit most materials are not open, but approved materials, developed by different agencies (e.g., City Research Agency) and approved at different levels: (1) national resources, such as the national curriculum (provided by the ministry); (2) regional adaptations of approved resources (e.g., textbooks are adapted for use in regional schools); (3) local/regional resources (e.g., City Research Agency had approved certain resources for use by teachers in Suzhou City; QQ groups); (4) school-based produced and approved resources (e.g., campus network resources developed by teachers in the TRG). For schools and teachers, these approved materials were said to be of good (approved) quality.

\subsection{Data collection strategies and analysis}

The research design was that of case study (Yin, 2004), aiming to investigate the resource systems of three selected mathematics teachers. These teachers were chosen on the basis of being regarded as experts by the education authorities (each of them was leading one of the three school level TRGs; their classes/students had achieved excellent examination results); and having varying years of teaching experience (Zhang - 23 years, Ji - 18 years, Jiang 8 years). From February to November 2014, two sets of in-depth semi-structured interviews were conducted with each teacher:

\footnotetext{
${ }^{2}$ QQ is an instant messaging software service developed since 1999 by the Chinese company Tencent, offering a variety of services, including online social games, and group and voice chats.
} 
- The first set of interviews focused on teachers' backgrounds and careers, and on their work/resource environments (schools in which they had worked; collective work with their peers; teaching resources used in their daily teaching and in particular for lesson preparation). Teachers were also asked to draw their SRRSs;

- The second set of interviews focused on the notion of expertise: the teachers were invited to (1) explain and define the notion of "expert" as compared to "novice" teacher; (2) describe how a teacher can develop such expertise; and (3) describe what they did over the past 5 years to further enhance their expertise.

Observations (field notes) were conducted regularly whilst visiting the school: participant observations were conducted on how the three teachers (individually) worked in the TRGs; how they participated in/led the school's activities; and how they used their resources during classroom instruction. These selected observations provided useful stimuli for discussion during interviews (e.g., discussions on the importance of collaborative work and how the expert teachers developed and supported such work in the TRGs).

In terms of processes, the data analyses involved category generation and saturation based on constant comparison, as advocated by Glaser and Strauss (1967). With the interviews, the SRRSs, and the observation field notes, we regard that we could track: (1) the ways the resources were conceived, used and connected (as perceived by teachers themselves); and (2) the 'expert' dimensions of each teacher's documentation work (as perceived by us). We did this by systematically noting: the resources cited; how they were used in class and in collective work; the ways the resources were linked (as described by the teachers); and our interpretation of how the resources, or resource systems, could be attributed to dimensions of expertise. We then compared these subjective views with our 'wholesome' case descriptions and knowledge of the contexts (also anchored in observations). We analyzed the explanations provided by the teacher, about their teaching, and their understanding of expertise and its development, and we investigated the possible connections between these explanations and the resources named/used. In such a way, that is linking the systematically developed dimensions with the 'wholesome' teacher cases, teachers' explanations about mathematics teaching and more importantly about teaching expertise, could be linked to particular resources, the resources' use, and the resource schemes. Moreover, we developed deeper understandings of each teacher's resource system, the similarities and differences between them, and the relationships between resource system and mathematics teaching expertise.

After transcribing (in Chinese) and translating (in English) the interviews, we realized that our reflections on translation were actually reflections on the theoretical choices made. In order to enhance the conceptual equivalence of notions when translating (e.g., Hantrais \& Mangen, 1996), several steps were taken: first, the interviewer (one of the authors) provided a first English translation, checked then by the second Chinese author. Thirdly, a third author (non-Chinese speaker) discussed, in English, with Chinese students (majoring in education) the different meanings of the keywords, and a new translation was produced based on negotiations. We contend that the translation of the Chinese texts into English needed delicate work of negotiation and comparing understandings, leading to a deeper understanding of the main concepts at stake (e.g., "resources"; "collective work"). 


\section{Findings}

In this section we present our findings and answer the research questions: we first develop and analyse the three cases ("within-case analysis"), before comparing them in a cross-case analysis with respect to teachers' resource systems, and finally with respect to teaching expertise.

\subsection{Case descriptions of the three expert teachers}

Jiang majored in mathematics and applied mathematics. He was a young "expert teacher": he gained this status after only 7 years of teaching, and he was now in his eighth year. He was also recently awarded "excellent class teacher", a district-level award. Though Jiang was a young teacher (born in 1985), he had taught two 'cycles' (one 'cycle' = Grades 10-12) of high school, which was rare amongst young teachers. Jiang had been specifically chosen to teach grade 12 , the graduating class, for the past 2 years because of excellent student examination results and his instructional performance. Typically, young teachers like him would not teach a graduating class, unless they had achieved remarkable teaching/examination results. His classes have always ranked top in tests, and he was in high esteem by his colleagues and school leaders.

In terms of developing expertise, Jiang was convinced that cooperation was necessary to enhance one's teaching, and he regarded the development and exchange of resources as crucial.

"Actually, in the end all teachers need cooperation, otherwise they will not go further in their professional development."

This, he thought, was particularly important for novice teachers, as they did not know the content of the whole teaching cycle (in high school: grades 10-12). He perceived the difference between an experienced and novice teacher in the following way:

"An experienced teacher can make variation whenever he wants, because he has met lots of items and has enough resources in his mind; he is a question bank himself, so he can change the items. But the novices always only focus on the ready-items [known items/ questions], and cannot make a variety ... and the students need more innovative items."

Jiang perceived an expert teacher as someone who:

- had his own "clear teaching style" and did "not imitate" others;

- was "liked by [colleague] teachers and students"; and

- conducted "front-line research" in teaching and learning.

For Jiang this meant conducting innovative projects; and having "the courage to challenge open classes and lectures" (possibly given by other experts). His own development had benefitted from a particular research network ("Research of Chinese Mathematics Problem Solving"), and his own continued efforts to combine theory (also research) and teaching practice, in order to develop his "own teaching style" and to achieve excellent results with his students in examinations.

In terms of lesson preparation Jiang explained that "most importantly" he would first outline/conceive the lesson/learning trajectory "by himself", knowing what the curriculum standards were, before turning to other resources (e.g., "teaching- guidance books/teacher 
guidelines, curriculum standards, and selected teaching-aid documents"). After the lesson, he mentioned, he would write down his reflections on: student thinking; their interactions; etc. What Jiang considered most important (his own words) for teachers' professional development was "reflection and sharing" of resources.

In terms of resources for lesson preparation and instruction, Jiang's first choice was the "lesson preparation group" (part of TRG, based on each grade), and secondly mathematics resource websites. Indeed, from Jiang's SRRS we could see that he used a large number of internet resources, such as forums, websites and QQ groups - these were (internet) forums where access was restricted to those participants assessed to be "excellent", who could contribute excellent resources. Jiang said that he had worked hard to get accepted, and to keep his membership, in selected QQ groups. For this, he had to produce and share his resources regularly, and the quality of the contributed resources was rigorously assessed. However, in return, he had gained access to download others' resources.

Jiang was proud that he had been good at collecting and organizing his resources over the years, and he had modified and appropriated them to become his resources. For example, he mentioned that he had collected past examination papers, students' 'error sets' (both in their homework and examinations), and selected (good students') error sets (for the examinations) over several semesters - he had sorted the documents on his home computer, as well as test paper preparations and lesson plans associated with examination preparation lessons. His resource system was digital: all was saved on his computers and network disk.

From Jiang's SRRS (Fig. 2) we can see that his resource system is well-structured, and divided into three parts: (1) his computer at home (e.g., searching for internet resources; storing them); (2) the computer in the office (used for e.g., preparing tests and lesson); and (3) the paper materials he had collected, which included two kinds of resources - primary resources (e.g., textbooks, teaching reference books); and generated resources (e.g., 'error sets' and
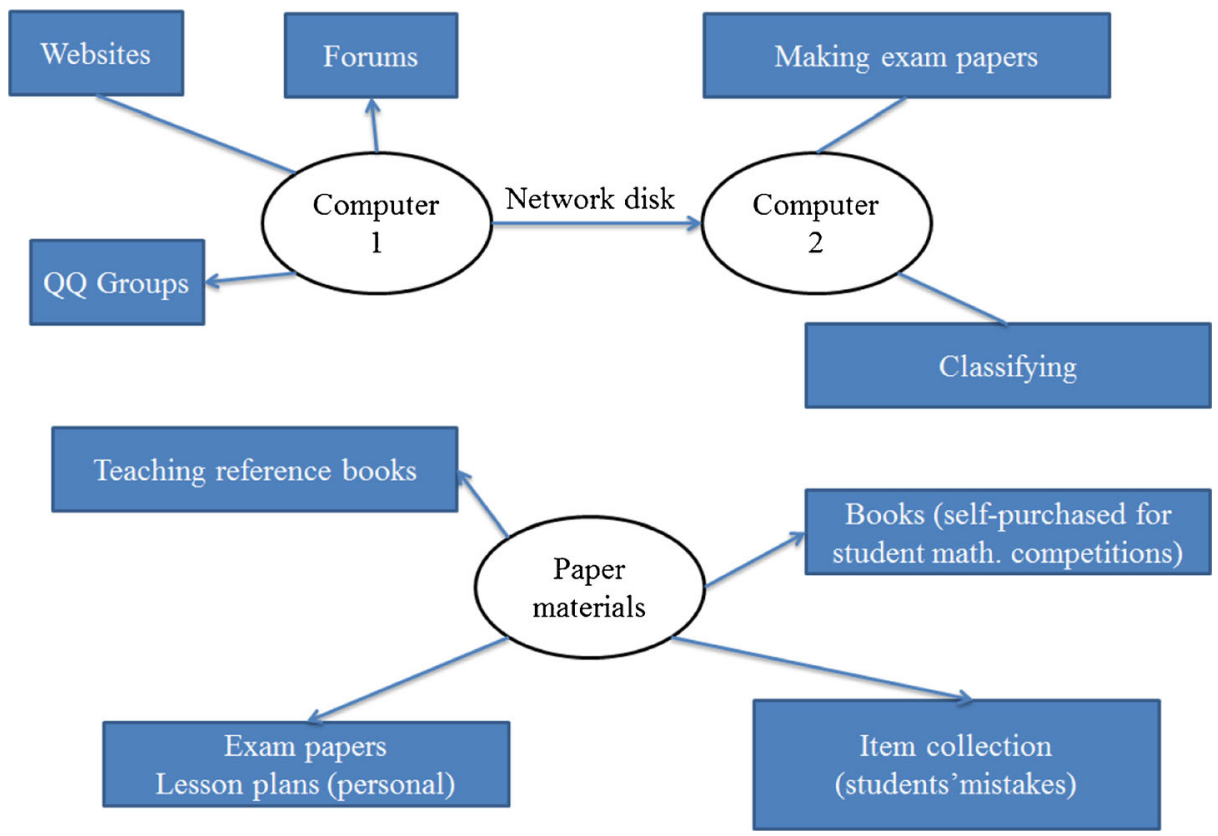

Fig. 2 The SRRS of Jiang 
examination preparation — see above) — according to him, he had a "complete set of resources".

Ji majored in mathematics education, and he was now a senior/expert teacher (at the time of the study), with 18 years of rich teaching experience from middle to high school. He was now the leader of the lesson preparation group of grade 11. Interestingly, he mentioned that in his previous schools the cooperation between teachers had been better than in his present school, and he also attributed this to the ratio between "young" and "mature" teachers: "the more mature, the less cooperation". Drawing a difference between novice and experienced teachers, Ji explained that

"A lesson can be prepared the same, but how to teach it differs. In lesson preparation, beside the content, there is also the teaching design ... but giving the lesson relies on how the teacher holds the class ... it will be useless if [the teacher] cannot achieve the teaching objectives, no matter how good the lesson plan is."

For Ji an expert teacher was "an expert in teaching his discipline; [who] had profound insights into teaching and [didactic] research; ... [and] was versed in both research projects and theory [papers]". In his view, in order to develop, novice teachers needed to persist on learning both teaching and didactic theory, apart from being able to "accumulate materials" (e.g., teaching experiences, reflections on many observed lessons (also different grades); and to set him/herself short-term as well as long-term "challenges"). In addition, novices had to "process abundant exercises", especially the examination questions, in order to "better adjust" their teaching and not "simply remain teaching the textbook [content]". Ji considered that this could also be done through research projects. As expert teacher, Ji's expertise was characterized by reflection on teaching and effective enactment of the curriculum.

In terms of resources, Ji mentioned online materials and journals, and also textbooks and teacher guides. However, he considered textbooks (and teacher guides) as "instrument/s" and not essential for an experienced teacher, simply for reference to provide the "objectives" for instruction. In fact he contended that young teachers tended to "rely too much on the textbooks and teaching guidance books", that they were often "not flexible enough" (because of little and insufficient teaching experience). In his day-to-day teaching Ji said that he did not communicate much with students; he rather got feedback from their written work, in particular homework. For his lesson preparation "the students [did not] play an important role, [but] ... what knowledge base they [had]", which he perceived to get from their written work.

Concerning Ji's resource system, he drew his resources (Fig. 3) according to the location, and almost all of his documentation work was located at school. As a "traditional [expert] teacher" he relied on his teaching experience, according to what he said in the interview, more than on other resources. In his resource system, the generated resources from his own experiences, feedback from pupil written work, and colleagues' comments played a much more important role than any "ready-made" resources.

Zhang had majored in mathematics education, and at the time of study had been teaching mathematics for 23 years; he was now a senior/expert teacher in the high school. At the same time, he was also seen as an academic leader and educational expert in his city, leading and advising on classroom research (e.g., conducting projects; writing papers) and classroom teaching. For example, he was in the process of conducting a national project (with TRGs) on "The application of logical thinking in high school mathematics teaching". For this, he had been chosen not only because of his teaching expertise, but also for his competence in information technology linked to mathematics teaching (he has conducted several projects 


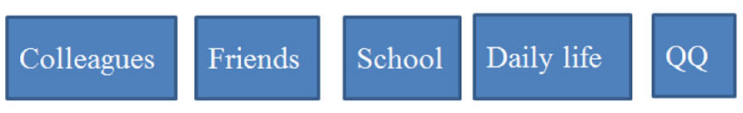

Materials for lesson preparation

\section{Puzzles (problems)}

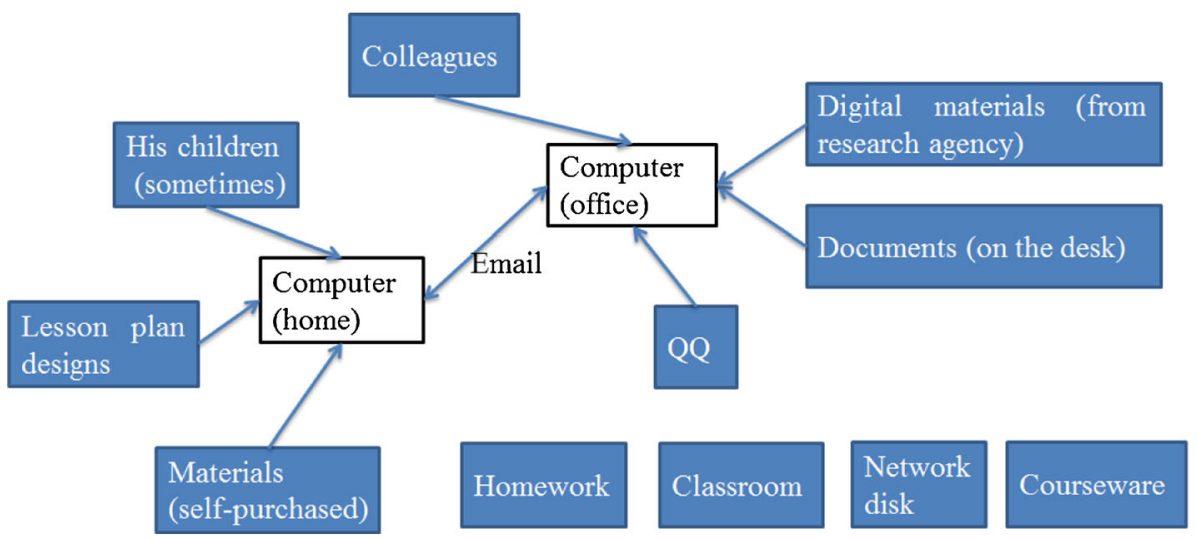

Fig. 3 The SRRS of Ji

involving educational technology). Within the school and the district he was known as the "specialist of ICT" (Information and Communication Technology). This was quite extraordinary, because he originally majored in mathematics education, and he then taught himself the technology aspects.

In terms of resources for teaching, Zhang instantly mentioned the QQ Campus Platform (see earlier explanation), his computer (in his office), and the TRG. However, he emphasized that he received most "enlightenment" from classroom teaching and student feedback (e.g., homework). Zhang described how he would prepare a lesson, in particular a new lessons: starting with the relevant documents (e.g., textbooks, teacher guides) as reference points, he would consider students' "characteristics" (e.g., learning level/s; weaknesses; problem areas); the "teaching situation" (e.g., requirements of the curriculum standards for that grade; whether open lesson or not); and the relevant tools (e.g., geometer sketchpad) associated with the relevant "learning methods" (e.g., "how to guide students to learn").

Interestingly, Zhang talked more about students and their "learning characteristics", how he involved their feedback (e.g., in homework) in his lesson preparations, than the other two teachers. He was clear that "teaching methods [were] different from learning methods", and that communication (amongst teacher and students) was an important part of learning: communication with students in terms of homework and tests; and direct communication (in class) about "learning methods" - in Zhang's view, these kinds of communication would be essential for learning.

Zhang drew his resource system (SRRS) in a very systematic way (Fig. 4); he divided his resources into three parts: digital; interpersonal; and paper resources. Unlike other teachers, he involved his smart phone: to compute; to do online searches; or to take photos. He knew his resource system well. 


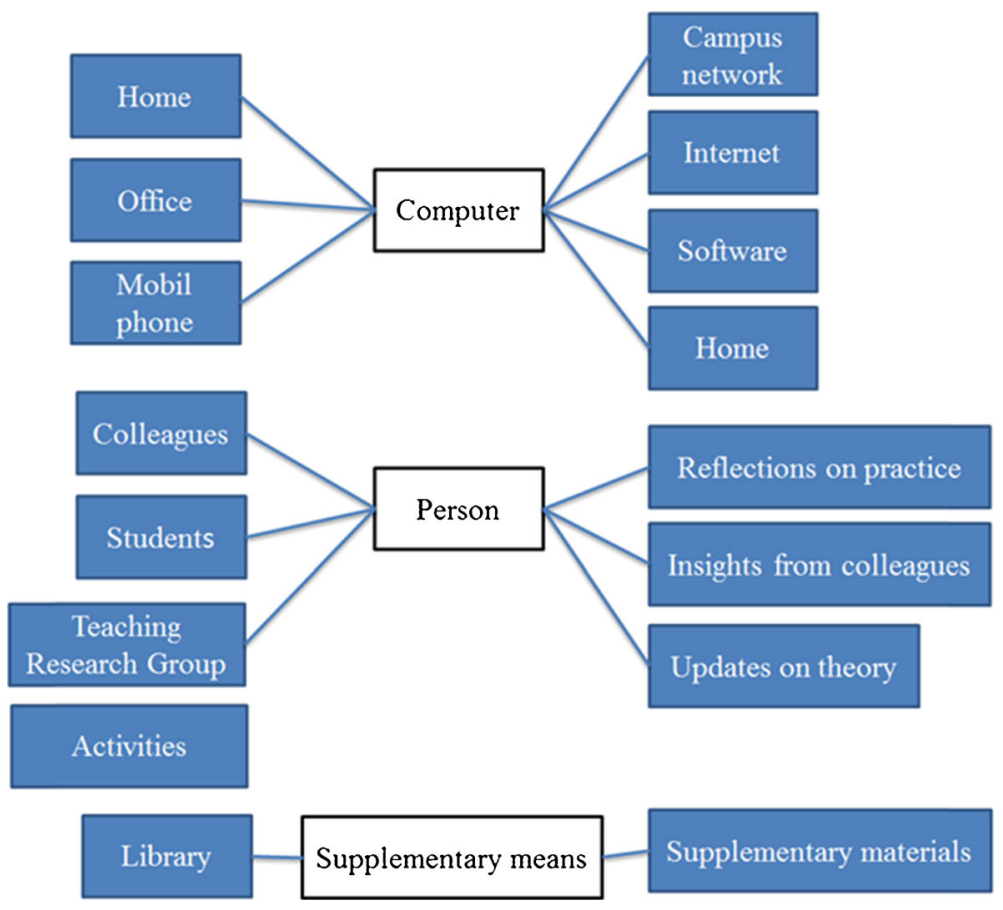

Fig. 4 The SRRS of Zhang

Zhang was explicit about his views on teaching expertise, and how to develop it. He divided the "growth process" into three stages: "firstly, a young teacher should focus on strengthening his professional proficiency" (e.g., being familiar with the [mathematical] knowledge system, the teaching methods and skills). Secondly, "after one or two cycles of high school teaching", s/he should focus on student learning, their development in learning mathematics - for him, this was "the basic objective of teaching" and included the "ways" of pupil thinking, "habits" of mind, and the "quality" of thinking, in order that students were provided with learning opportunities that guided them to a higher level of cognition, and at the same time helped them to form suitable habits of working and mind. Thirdly, a teacher should focus on research of new teaching ideas and theoretical research, which would direct him/her and at the same time provide a reference for his/her development.

In his view, too many (novice) teachers would spend too much energy on teaching methods and on solving specific (mathematical) questions, whereas the emphasis should be, he contended, on "training students' [thinking] ability", so that they could "think independently, explore independently". Hence, his emphasis was on developing student thinking, rather than "content teaching".

In terms of collaboration Zhang was clear that collaboration and resource-sharing was necessary for all teachers to enhance their teaching, but in particular for novice teachers. Indeed, he claimed that "a novice cannot develop without an active team and the motivation for self-development", and that this guidance from experienced teachers was "indispensable". However, he also stressed that "self-learning" was "essential" too, such as observing lessons, reflecting on lessons, summarizing teaching activities, actively participating in projects, etc. 


\subsection{Resources and resource systems compared}

From both the literature and the interviews with the three "expert" teachers, it was clear that particular resources (e.g., textbooks) still played an important role in/for mathematics teaching and learning. At the same time various other resources attracted teachers, often to enrich and expand on textbooks (Ding, 2010), and the three teachers provided different types of resources that characterised their resource environments. Four groups of keywords related to resources could be identified, and categorized in the following way: text resources; digital resources; resources from interactions with colleagues; and with students. The first two groups of resources (text/digital resources) were mainly used as information for and materials in/for instruction. The other two groups (personal resources: resources from interaction with colleagues and students) appeared to be more 'dynamic' for teachers. "Learning from student feedback" (written, e.g., homework; or feedback in class) were resources emphasised in particular by Zhang, who had extensive teaching experience: he paid much attention to students' learning/thinking processes, and for him, "listening to students" seemed to be one of the most valuable resources for fine-tuning his teaching. For the other two teachers pupils' written work appeared to be more important: e.g., Jiang's "students' error solutions sets".

Interestingly, during the interview Jiang mentioned documents and students most (23 times); Ji talked mostly about textbooks and materials (12 and 11 times respectively); whilst Zhang mentioned students 24 times, as well as projects (17 times) and network (16 times). In addition, Jiang, who was only 30 years old and had only 8 years of teaching experience, paid much attention to on-line resources, such as network, QQ groups, etc.; Ji appreciated more the material/text resources, and visible resources, such as open classes; whilst Zhang appeared to emphasise research project work, his network, and the students in class, as valuable resources. Referring to the seven strands provided by Schoenfeld and Kilpatrick (2008), we argue that Zhang emphasised knowing students (both as thinkers and learners); whilst Ji paid attention to self-reflection on his practice; and Jiang stressed the resources related to school mathematics.

From a more qualitative analysis it can be argued that each teacher case had its individual characteristics: Zhang was clearly the most experienced (and oldest) teacher amongst the three. He had a very clear view of the role and importance of the resources he used (and mentioned), evidenced by the structured way he drew his resource system. Interestingly, although he was older than most of his colleagues, he had developed high competence in the use of ICT resources (by self-education), and he was known by his colleagues as a specialist in this area. A second significant aspect of his description of resources was his repeated mention of "awareness of cultivating students' ability": he clearly listened and attended to student thinking, one of the hallmarks of good mathematics teaching and professional development in the west (e.g., Jacobs, Lamb, \& Philipp 2010). Ji appeared to be a traditional and proficient teacher, whose main resource seemed to be his vast teaching experience: his resource system seemed less structured, but included many aspects of what the other two teachers mentioned. Jiang was by far the youngest teacher, but apparently the 'fastest growing' teacher: with only 8 years of teaching experience, he had taught the (upper secondary) cycle twice, and he appeared very systematic in organising his resources digitally. One of the characteristics of his resources was the bank of test papers with associated 'common problems' (misconceptions) of pupils, and pupils' model answers.

Moreover, differences between the three teachers' systems can be shown when the three expert teachers talked about the modification, that is when they used/adapted new teaching 
resources in/for their own classes: Jiang seemed to often modify his whole resource system, and to flexibly adapt the system to new teaching situations - it appeared dynamic. He had abundant digital resources collected from various websites, forums and QQ groups: he had a huge 'bag of tools' at his disposal. Ji clearly valued developing lesson plans and teaching reflections, working on his own, and he was more conservative in sharing his ideas and resources - his resource system appeared static. Zhang, very knowledgeable in terms of IT resources, provided evidence for a living and growing resource system: with no previous educational background of ICT, Zhang developed an interest and expertise in IT resources (he was very good at graphing software), and he was now known to have developed many resources in the area of "Graphing and geometry".

\subsection{Mathematics teaching proficiency}

In terms of perceptions of proficiency in mathematics teaching and how to develop it, there were several similarities, but also differences amongst the three teachers. In terms of similarities, all three teachers' answers shared the following features: good mathematics instruction ("good teacher"- translation); and keeping pace with advanced teaching ideas ("good researcher"- translation). In particular Jiang, who had only recently achieved the level of expertise, emphasised the efforts to combine "theory and teaching practice" and "keeping pace with 'frontier' theory"-one of the strands of Yang's (2010) outline. For Jiang, the QQ network was the main access for his professional learning, not only to enhance his teaching, but also his learning as a 'scholar'. Interestingly, Schoenfeld and Kilpatrick (2008) dimensions of proficiency say much about the first (good teaching), but there do not seem to be mention of the second: keeping up with recent/scholarly knowledge/theories on teaching and learning mathematics. This may be for two reasons: (1) In the same way as TRGs (or similar groups) are not (yet) an integral part of every ('Western') mathematics teacher's professional development, the notion of "research" is not typically associated with teachers' work in schools. However, in Schoenfeld and Kilpatrick's dimensions of proficiency, reflection on practice is emphasised - this can be interpreted that practising teachers are not (yet) expected to conduct research, but "inquire" into their own practice. (2) The term "research" is used in different ways: as we observed and noted, TGSs were groups exploring mathematics teaching in a very practical way, and not necessarily following strict guidelines for research, nor did they include research articles - so, the only way that research on mathematics teaching could reach the school teachers would have been through the expert teacher, who was expected to 'digest' theories and research studies, for dissemination in discussion with teachers.

There were also interesting differences amongst the three teachers: whereas Zhang outlined a three-step growth progression to become an expert teacher, and he was clear that this development would not be possible without a team and the support of expert teachers, Ji and Jiang provided characteristics of expert teachers. These were both interesting and revealing: whilst $\mathrm{Ji}$ characterised expert teachers in terms of their profound knowledge of teaching (acquired through reflection on one's own and others' teaching), and the accompanying theories - a traditional approach; Jiang portrayed an expert teacher as someone who could teach differently, had his/her own style (and of course conduct research). Jiang emphasised that this could not be done by "imitation", but "thinking on one's own" - a creative approach. These notions 
are clearly in line with both Berliner $(1987,2004)$ and Schoenfeld and Kilpatrick (2008).

It appeared (from what teachers said) that, different from Ji and Jiang, Zhang had already reached his 'ideal' expert stage, not only for his rich experiences in conducting projects, but also in his practice as an excellent teacher/practitioner, who would carefully consider his students' prior knowledge and developing needs.

\section{Discussion and conclusions}

In this section we draw the conclusions from the main findings. These are provided in three parts: (1) the importance of resources and of sharing them; (2) professional identity of expert teachers; and (3) developing expertise.

\subsection{The importance of resources and of sharing them}

Looking across the cases of the three expert teachers, it is clear that resources, both text/digital resources as well as human resources (colleagues and pupils), are a crucial influence on teachers' identity and instructional practice. Moreover, the ways a teacher's resource system is structured, provide researcher not only with a tool/stimulant for eliciting intricate knowledge of participants' perceptions of their work, but more importantly with indications of their professional beliefs and practices.

One of the striking points in the three teachers' talk about resources was the emphasis on the collective aspect of developing, and more importantly of 'sharing resources' in order to improve instructional practices of all members. This was most evident in Jiang's QQ network and his own fast development as an expert teacher. The collective work on and sharing of resources was anchored in the TRGs, and every teacher had to participate in those. Public lessons were another way of working collectively on resources. In the TRGs, as in the QQ groups, "shared instructional products" (Morris \& Hiebert, 2011) were produced and trialed. These groups shared "the same problems for which the products offered solutions"; and the products were "jointly constructed and continuously improved" (p.5). As Hiebert, Gallimore, and Stigler (2002) describe, resources such as lesson plans were treated "as products that can be shared and examined publicly, that could be improved over time through repeated trials in multiple classrooms". As evidenced by Jiang, he shared and acquired more and more detailed knowledge about particular resources, his materials (including lesson plans) were annotated and updated by embedding his knowledge into the revised materials and plans.

\subsection{The professional identity of expert teachers}

It is interesting to note that there seems to be a clear notion of mathematics teaching expertise in China, whereas in Europe (and the United States) this seems to be less developed. Our three teachers saw themselves, and were regarded by the authorities and colleagues, as expert teachers, with Jiang reaching this level after only 8 years of teaching. Hence, we argue that there was a clear professional identity (Beijaard, Meijer \& Verloop, 2004) as expert teacher: e.g., as leading coordinators of teaching research activities; as school-based researchers; as developers of teaching resources; as teacher educators (for novices and non-expert teachers). Despite these similarities the 
three teachers had very different resource systems: Zhang's system was highly structured; Ji's more distributed; Jiang's structured and focused on IT/networks, organized towards assessment. Moreover, although working in the same school/environment, the three teachers had different perceptions of what expertise meant, and they emphasized different foci of their professionalism. Whilst Ji might be called a "traditional" expert teacher ('simply' a very good and reflective teacher); Jiang (the youngest) was experimentally creative and dynamic, albeit assessment-driven, an active member of the QQ group/s. Zhang was the most "scholarly/academically experienced" and the most pupil-oriented of the three. We argue that whilst the notion of expert teacher was relatively well-defined in China, there were many nuances in our Chinese teachers' expertise.

\subsection{Developing expertise}

Our three teachers not only offered professional (expert) support for mathematics instruction in schools (e.g., in the TRGs), but they were also expected to provide exemplary mathematics instruction (e.g., in open lessons). It appeared that one of the roles of expert teachers was to afford professional learning experiences for colleagues, in order to foster and implement reform-based instructional practices that embody current reforms in Chinese mathematics education (e.g., problem-solving). Research (Cramer, Post, \& del Mas, 2002) has shown that professional development could only be effective and change teachers' practice, if it was paired with classroom-based support before, during and after lessons: our expert teachers were working with mathematics teachers in schools, in the TRGs, as close as they could be to practice.

At the same time the TGS learning environments were also influenced by members' conceptions of "good teaching"; by perceptions of a teacher's role in the school; and by the culture of the school (as the workplace), amongst other factors. These, in turn, it could be argued, were influenced by socio-mathematical norms (Yackel \& Cobb, 1996) of the expert teachers, and the community in which they were working. Whilst our three teachers had a varied and nuanced understanding of how to develop expertise in mathematics teaching, they agreed on several aspects, and these would clearly provide important sign-posts for aspiring teachers. Hence, one negative effect of TGS work, one could argue, would be the alignment of teaching practices of TRG members with the expert teacher's understanding of quality teaching - this would be the topic for further study. However, from the existing literature it is clear that coaches and/or "expert teachers" are crucial in directing and supporting less experienced teachers in school (Haggarty, Postlethwaite, Diment, \& Ellins, 2009).

In summary, we argue, firstly, that the "lens of resources" provides a useful tool for examining mathematics teaching expertise; a tool that brings to the surface many different aspects of expertise by linking teaching to the materials with which teachers interact and work on a daily basis. Secondly, from our study we draw as implications for the mathematics education community that a study of expertise highlights selected'underdeveloped', or 'underappreciated', aspects of mathematics teaching, and it brings up 'new' questions (e.g., is scholarly work necessary for developing expertise?), whilst at the same time showing the variety of approaches to teaching expertise, even if they are given the same name. We wonder whether the notion of mathematics teaching expertise could find a 'revival', a renewed and appropriately 
readjusted corresponding 'equivalence' in Western perceptions of mathematics teaching.

Open Access This article is distributed under the terms of the Creative Commons Attribution 4.0 International License (http://creativecommons.org/licenses/by/4.0/), which permits unrestricted use, distribution, and reproduction in any medium, provided you give appropriate credit to the original author(s) and the source, provide a link to the Creative Commons license, and indicate if changes were made.

\section{References}

Ball, D. L., Thames, M. H., \& Phelps, G. (2008). Content knowledge for teaching: What makes it special? Journal of Teacher Education, 59, 389.

Beijaard, D., Meijer, P. C., \& Verloop, N. (2004). Reconsidering research on teachers' professional identity. Teaching and Teacher Education, 20, 107-128.

Berliner, D. C. (1987). In pursuit of the expert pedagogue. Educational Researcher, 15, 5-13.

Berliner, D. C. (2004). Describing the behaviors and documenting the accomplishments of expert teachers. Bulletin of Science Technology and Society, 24(3), 200-212.

Blömeke, S., \& Kaiser, G. (2012). Homogeneity or heterogeneity? Profiles of opportunities to learn in primary teacher education and their relationship to cultural context and outcomes. ZDM - The International Journal on Mathematics Education, 44(3), 249-264.

Cai, J., \& Wang, T. (2010). Conceptions of effective mathematics teaching within a cultural context: Perspectives of teachers from China and the United States. Journal of Mathematics Teacher Education, 13, 265-287.

Cramer, K. A., Post, T. R., \& del Mas, R. C. (2002). Initial fraction learning by fourth- and fifth-grade students: A comparison of the effects of using commercial curricula with the effects of using the rational number project curriculum. Journal for Research in Mathematics Education, 33(2), 111-144.

Ding, G. (2010). National teacher professional development surveys. Shanghai: East China Normal University Press.

Fenstermacher, G. D., \& Richardson, V. (2005). On making determinations of quality in teaching. Teacher College Record, 107(1), 186-213.

Glaser, B., \& Strauss, A. (1967). The discovery of grounded theory. Hawthorne, NY: Aldine Publishing Company.

Gueudet, G., Pepin, B., \& Trouche, L. (Eds.). (2012). From text to 'Lived' resources: Mathematics curriculum materials and teacher development. New York: Springer.

Gueudet, G., Pepin, B., \& Trouche, L. (2013). Collective work with resources: An essential dimension for teacher documentation. ZDM - The International Journal on Mathematics Education, 45(7), 1003-1016.

Gueudet, G., \& Trouche, L. (2009). Towards new documentation systems for mathematics teachers? Educational Studies in Mathematics, 71(3), 199-218.

Haggarty, L., Postlethwaite, K., Diment, K., \& Ellins, J. (2009). An examination of beginning teacher learning during the induction year. Paper presented at the British Educational Research Association Annual Conference, University of Manchester, UK.

Hantrais, L., \& Mangen, S. (Eds.). (1996). Cross-national research methods in the social sciences. London: Pinter.

Hiebert, J., Gallimore, R., \& Stigler, J. (2002). A knowledge base for the teaching profession: What would it look like and how can we get one? Educational Researcher, 31(5), 3-15.

Hill, H.C., Blunk, M., Charalambous, C., Lewis, J., Phelps, G.C., Sleep, L., ... Ball, D.L. (2008). Mathematical knowledge for teaching and the mathematical quality of instruction: An exploratory study. Cognition and Instruction, 26, 430-511.

Huang, R., Su, H., \& Xu, S. (2014). Developing teachers' and teaching researchers' professional competence in mathematics through Chinese Lesson Study. ZDM - The International Journal on Mathematics Education, 46, 239-251.

Jacobs, V. R., Lamb, L. L. C., \& Philipp, R. A. (2010). Professional noticing of children's mathematical thinking. Journal for Research in Mathematics Education, 41(2), 169-202.

Li, Y., \& Huang, R. (2008). Chinese elementary mathematics teachers' knowledge in mathematics and pedagogy for teaching: The case of fraction division. ZDM - The International Journal on Mathematics Education, 40, 845-859. 
Li, Y., Huang, R., \& Yang, Y. (2011). Characterizing expert teaching in school mathematics in China: A prototype of expertise in teaching mathematics. In Y. Li \& G. Kaiser (Eds.), Expertise in mathematics instruction: An international perspective (pp. 167-195). New York: Springer.

Li, Y., \& Kaiser, G. (Eds.). (2011). Expertise in mathematics instruction: an international perspective. New York: Springer.

Li, Y., Tang, C., \& Gong, Z. (2011). Improving teacher expertise through master teacher work stations: A case study. ZDM-The International Journal on Mathematics Education, 43(6-7), 763-776.

Ma, L. P. (1999). Knowing and teaching elementary mathematics. New Jersey: Lawrence Erlbaum Associates Publishers.

Morris, A. K., \& Hiebert, J. (2011). Creating shared instructional products: An alternative approach to improving teaching. Educational Researcher, 40(1), 5-14.

OECD (Organization for Economic Cooperation and Development). (2010). Education at a Glance 2010 OECD indicators. Retrieved from http://www.oecd.org/about/publishing/corrigenda.htm. August 102015

Olson, J. (1992). Understanding teaching: Beyond expertise. Milton Keynes: OU Press.

Rabardel, P. (1995). Les hommes et les technologies, approche cognitive des instruments contemporains. Paris: Armand Colin.

Rowland, T., \& Ruthven, K. (Eds.). (2011). Mathematical knowledge in teaching. New York: Springer.

Schoenfeld, A. H., \& Kilpatrick, J. (2008). Toward a theory of proficiency in teaching mathematics. In T. Wood \& D. Tirosh (Eds.), International handbook of mathematics teacher education: Vol. 2. Tools and processes in mathematics teacher education (pp. 321-354). Rotterdam: Sense Publishers.

Shulman, L. S. (1986). Those who understand: Knowledge growth in teaching. Educational Researcher, 15(2), 4-14.

Stigler, J., \& Hiebert, J. (1999). The teaching gap: Best ideas from the world's teachers for improving education in the classroom. New York: Free Press.

Yackel, E., \& Cobb, P. (1996). Socio-mathematical norms, argumentation, and autonomy in mathematics. Journal for Research in Mathematics Education, 27(4), 458-477.

Yang, X. (2010). Conceptions and characteristics of expert mathematics teachers in China. Dissertation University of Hong Kong. Chongqing, China: Springer Spektrum.

Yin, R. K. (2004). The case study anthology. Thousand Oaks: Sage Publications. 